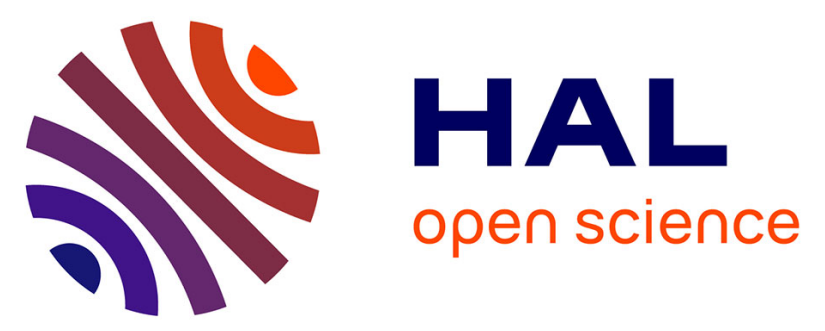

\title{
Importance of Integration and Implementation of Emerging and Future Mercury Research into the Minamata Convention
}

\author{
Mae Sexauer Gustin, David C. Evers, Michael S Bank, Chad R
}

Hammerschmidt, Ashley Pierce, Niladri Basu, Joel Blum, Paco Bustamante, Celia Chen, Charlie Driscoll, et al.

\section{To cite this version:}

Mae Sexauer Gustin, David C. Evers, Michael S Bank, Chad R Hammerschmidt, Ashley Pierce, et al.. Importance of Integration and Implementation of Emerging and Future Mercury Research into the Minamata Convention. Environmental Science and Technology, 2016, 50, pp.2767-2770. 10.1021/acs.est.6b00573 . hal-01337321

\section{HAL Id: hal-01337321 \\ https://hal.science/hal-01337321}

Submitted on 2 Feb 2017

HAL is a multi-disciplinary open access archive for the deposit and dissemination of scientific research documents, whether they are published or not. The documents may come from teaching and research institutions in France or abroad, or from public or private research centers.
L'archive ouverte pluridisciplinaire HAL, est destinée au dépôt et à la diffusion de documents scientifiques de niveau recherche, publiés ou non, émanant des établissements d'enseignement et de recherche français ou étrangers, des laboratoires publics ou privés. 


\title{
Importance of Integration and Implementation of Emerging and Future Mercury Research into the Minamata Convention
}

\author{
Mae Sexauer Gustin ${ }^{* 1}$, David C. Evers ${ }^{2}$, Michael S. Bank ${ }^{3}$, Chad R. Hammerschmidt ${ }^{4}$, Ashley Pierce ${ }^{5}$, \\ Niladri Basu ${ }^{6}$, Joel Blum ${ }^{7}$, Paco Bustamante ${ }^{8}$, Celia Chen ${ }^{9}$, Charlie T. Driscoll ${ }^{10}$, Milena Horvat ${ }^{11}$, Dan \\ Jaffe $^{12}$, Jozef Pacyna ${ }^{13}$, Nicola Pirrone ${ }^{14}$, Noelle Selin ${ }^{15}$
}

\author{
${ }^{1}$ Mae Sexauer Gustin mgustin@cabnr.unr.edu \\ Department of Natural Resources and Environmental Science, University of Nevada-Reno, Reno, NV, USA, 89557
}

2 David C. Evers david.evers@briloon.org

Biodiversity Research Institute, 276 Canco Road, Portland, Maine USA 04103

${ }^{3}$ Michael S. Bank mbank@eco.umass.edu

Department of Environmental Conservation, University of Massachusetts Amherst, 160 Holdsworth Way, Amherst, MA, USA 01003

${ }^{4}$ Chad R. Hammerschmidt chad.hammerschmidt@wright.edu

Department of Earth \& Environmental Sciences, Wright State University, 3640 Colonel Glenn Hwy., Dayton, OH, USA, 45435

${ }^{5}$ Ashley Pierce ash.pie4@gmail.com

Department of Natural Resources and Environmental Science, University of Nevada-Reno, Reno, NV, USA, 89557

${ }^{6}$ Niladri Basu niladri.basu@mcgill.ca

Department of Natural Resource Sciences and School of Dietetics and Human Nutrition, McGill, University, Montreal, PQ Canada

7 Joel Blum jdblum@umich.edu

Department of Earth and Environmental Sciences University of Michigan, Ann Arbor, MI 48109

8 Paco Bustamante paco.bustamante@uni-Ir.fr

Littoral, Environnement et Sociétés (LIENSs), UMR 7266 CNRS-Université La Rochelle, 2 rue Olympe de Gouges,

17000 La Rochelle, France

${ }^{9}$ Celia Chen Celia.Y.Chen@dartmouth.edu

Dartmouth College, Department of Biological Sciences, Hanover, New Hampshire 03755, United States

${ }^{10}$ Charlie T. Driscoll ctdrisco@syr.edu

Syracuse University, Syracuse, New York 13244, United States

11 Milena Horvat milena.horvat@ijs.si

Department of Environmental Sciences, Jožef Stefan institute, Ljubljana, Slovenia

12 Dan Jaffe jaffe@uw.edu

Physical Sciences Division, School of Science and Technology, University of Washington-Bothell, Bothell, WA 98011-8246

13 Jozef Pacyna jozef.pacyna@nilu.no

Norwegian Institute for Air Research, Kjeller, 2027 Norway

${ }^{14}$ Nicola Pirrone pirrone@iia.cnr.it

CNR-Institute of Atmospheric Pollution Research, Rome, Italy

15 Noelle E. Selin selin@mit.edu

Institute for Data, Systems and Society and Department of Earth, Atmospheric and Planetary Sciences, Massachusetts Institute of Technology Cambridge, MA 02139-4307 USA

*Corresponding author: Mae Sexauer Gustin mgustin@cabnr.unr.edu 


\section{Introduction}

Since the Industrial Revolution, and before, human actions have enhanced the production and emissions of mercury $(\mathrm{Hg}$ ), as well as climate changing gases (ozone, nitrous oxide, methane, and carbon dioxide). Burning of fossil fuels, mining, and other human activities, have increased the cycling of $\mathrm{Hg}$ at the Earth's surface (by at least 200\%), increasing human and wildlife exposure (1). Without abatement of $\mathrm{Hg}$ releases, this pattern is expected to continue into the future $(1,2)$. Under the United Nations Environment Programme (UNEP), countries negotiated the Minamata Convention on Mercury, a legally binding agreement intended "to protect human health and the environment from anthropogenic emissions and releases of mercury and mercury compounds" (Article 1 in ref 3). To date, the Convention has 128 signatories. The Convention will enter into force once it is ratified by 50 nations. With the Minamata Convention, global society has a regulatory mechanism to decrease environmental $\mathrm{Hg}$ loadings. Together with the reduction of climate changing anthropogenic gases through the Paris Climate Agreement, these global environmental policies should work toward protecting Earth for future generations. In order to achieve such long-term and far-reaching policy goals, it is essential that $\mathrm{Hg}$ be managed as a persistent contaminant. Recognizing that once released it actively cycles in the environment for hundreds-to-thousands of years before being buried in sediment (4).

The Convention builds upon scientific knowledge of global sources and supply, sinks, and reservoirs of $\mathrm{Hg}$, coupled to linkages with human and wildlife exposures, and related health impacts $(5,6)$. The atmosphere is the major transport pathway for distribution of $\mathrm{Hg}$ globally. Exchange of $\mathrm{Hg}$ among reservoirs (atmosphere, lithosphere, biosphere, and hydrosphere), and the amount present in each reservoir, are estimated using computational models based on limited spatial and temporal measurements of $\mathrm{Hg}$ concentrations, particularly in the atmosphere and ocean. Moreover, accuracy of model projections depends on the scientific knowledge of processes and mechanisms that affect transport, transformations, and fate of $\mathrm{Hg}$. Our knowledge of global cycling of $\mathrm{Hg}$ continues to be refined as a result of measurements and fundamental research. It is therefore essential that the Convention, and other policies, consider evolving scientific understanding as implementation moves forward. Here, we identify, and discuss, critical and emerging areas of investigation that are fundamental to the successful implementation of the Minamata Convention.

\section{Uncertainty of atmospheric Hg measurements made in the past and impact on understanding of the Hg biogeochemical cycle}

There are three forms of atmospheric $\mathrm{Hg}$ : gaseous elemental (GEM), gaseous oxidized (GOM), and particulate bound (PBM) (Figure 1). A single type of instrumentation has been used to measure these forms for the past $\sim 15$ years. Recently, it has been demonstrated that measurements made with this technology underestimate GOM concentrations by as much as a factor of 2-13. Moreover, sampling efficiency for GOM is impacted by interferences with ozone and water vapor (7). Quantifying atmospheric concentrations of GOM is critical, because of its bioavailability to ecosystems. Underestimates of GOM also result in biased low values for modeled dry deposition.

Deposition of reactive mercury ( $R M=G O M+P B M$ ) supplies complexes of inorganic $\mathrm{Hg}$ that can undergo abiotic and biological transformations on surfaces and in water. Importantly, inorganic or $\mathrm{Hg}$ (II) can be converted to methylmercury, a form of $\mathrm{Hg}$ that causes neurological, cardiovascular, and reproductive health effects in humans (8) and wildlife (9). Photochemical reactions reduce $\mathrm{Hg}(\mathrm{II})$ to GEM, resulting in emission back to the atmosphere and continuous cycling of $\mathrm{Hg}$ between reservoirs. Thus, 1 ) it is important to make accurate calibrated measurements of RM; and 2) understand that an atom of $\mathrm{Hg}$ remains available for uptake by organisms until sequestered.

Oxidants in the atmosphere cause the chemistry and concentration of GOM to vary across space and time, affecting atmospheric residence time and potential transfer to aquatic and terrestrial ecosystems through deposition processes (ref 7 and references therein). Air at a pristine high-elevation site, for example, can have higher GOM concentrations than at an urban site due to oxidation and production 
above the planetary boundary layer (where humans live). Atmospheric oxidants and $\mathrm{Hg}$ have interwoven biogeochemical cycles, and should not be considered independently. In order to understand the effectiveness of policies made regarding $\mathrm{Hg}$, and other air pollutants, $\mathrm{Hg}$ chemistry and concentrations need to be measured to monitor success. An ongoing, long-term, and successful example is the National Atmospheric Deposition Program that has monitored sulfur, nitrogen, and other compounds in wet deposition, while power plants and industries in the United States implemented controls on emissions.

Atmospheric deposition is the dominant source of $\mathrm{Hg}$ to the ocean. Methylation reactions within the water column result in methylmercury production and bioaccumulation in ocean fish, consumption of which is the primary exposure pathway of humans to $\mathrm{Hg}$ (2). Surface and intermediate waters of the ocean have experienced the greatest impact of anthropogenic $\mathrm{Hg}$ emissions (10). Future concentrations of methylmercury in marine ecosystems and their inhabitants will depend on loadings of RM from the atmosphere, physicochemistry, and the effects of climate change on $\mathrm{Hg}$ methylation rates. Thus, we need to understand the magnitude of RM deposition to the ocean.

\section{Emerging issues due to new information regarding atmospheric measurements}

There are at least four emerging issues related to atmospheric $\mathrm{Hg}$, based on refereed literature, that raise science-based concerns for consideration when implementing the Minamata Convention. Each issue impacts ecosystem health upon which humanity depends; we need to recognize that 1 ) $\mathrm{dry} \mathrm{Hg}$ deposition is not well quantified and is greater than wet deposition in most locations around the world; 2) there are significantly greater concentrations of RM in the atmosphere than previously realized; 3 ) methylation of atmospherically derived $\mathrm{Hg}$ is an important process in the open ocean; and 4) global models are constrained by a lack of high-quality emission inventory data and model uncertainty estimates are considerable.

Without accurate measurements, modelers cannot develop and test robust models, and, by extension, policy makers cannot develop effective regulations. Critical limitations in models have garnered significant interest within the scientific community and among policy makers. Specifically, models are based on emission inventories that have high uncertainties or simply do not exist. Not all emission sources are considered, such as nonpoint sources and unquantified coal-burning processes. Importantly, there is a poor understanding of emissions from artisanal small-scale gold mining (ASGM). Current models indicate that $\mathrm{Hg}$ emissions from ASGM activities may be greater than coal-fired power plants ( $37 \%$ versus $24 \%$ of total; ref 6 ). Additionally, emissions from biomass burning, natural $\mathrm{Hg}$ sources, and legacy impacts of anthropogenic emissions are not considered adequately in the global mercury cycle.

Chemistry of emissions from different sources needs to be considered for these will influence the scale and range of $\mathrm{Hg}$ transport (local, regional, and/or global). Current models 1 ) are evaluated based on limited data for atmospheric GOM and dry deposition; 2) do not consider the presence of different compounds of $\mathrm{Hg}$ in the atmosphere; and 3) apply reaction rate constants that are either highly uncertain or unknown.

Statistical rigor, standardization, and reproducibility are needed for all future air $\mathrm{Hg}$ measurements. Standard operating protocols are also required. A harmonization of data collection and management of a central platform for assessing spatial $\mathrm{Hg}$ gradients and patterns at a global scale have been initiated (e.g., Global Mercury Observation System; ref 11). However, prior to implementation improved methods for determination of atmospheric $\mathrm{Hg}$ species and forms need to be developed. This will provide a platform for better modeling of dry deposition. Policy relevant air-monitoring programs at strategic locations are foundational to support a successful $\mathrm{Hg}$ abatement program. Emerging methods, such as mercury stable isotope measurements, are important tools for tracing local sources and deposition of $\mathrm{Hg}$, and to probe the nature of biogeochemical transformations of mercury in the atmosphere and after deposition to land and water bodies (12). 


\section{Continuing uncertainties for biological measurements}

Current environmental $\mathrm{Hg}$ loadings have significant health impacts on fish and wildlife populations around the world, causing abnormal behaviour (9), reduced reproductive success (13), and ultimately increased overall risk to population-level health. The extents of adverse impacts are poorly documented for fish and wildlife populations, and there is particular concern for species foraging in wetland habitats. Such areas are sensitive to $\mathrm{Hg}$ input because of high methylation rates and increased biomagnification associated with extended trophic food webs.

Based on the Minamata Convention (ref 3; Article 16 and 19), measurements of $\mathrm{Hg}$ concentrations need to be conducted on key taxa (i.e., fish, sea turtles, birds, marine mammals), and humans, that are representative for tracking changes in environmental $\mathrm{Hg}$ loads. However, it is not feasible to monitor all taxa across comprehensive spatial and temporal scales, and thus customized biomonitoring programs need to be designed that capitalize on strategic measurements using the proper bioindicators, tissue types, time of year, habitats, and geographic locations (14). Consideration is also needed regarding trophic position and feeding habitat of bioindicators as both influence $\mathrm{Hg}$ body burdens.

There is high uncertainty in models that use abiotic Hg compartments (e.g., air, sediment, water) to predict biomagnification and bioaccumulation of methylmercury, especially for high trophic level biota. Therefore, because of the complex behavior of $\mathrm{Hg}$ once it enters an ecosystem, the effectiveness of $\mathrm{Hg}$ emission reduction policies need to be monitored through biota. For example, the Canadian Clean Air Regulatory Agenda (CARA) Mercury Science Program used $\mathrm{Hg}$ concentrations in fish and an obligate avian piscivore (i.e., the common loon, Gavia immer) to monitor the success of national regulations on $\mathrm{Hg}$ emissions. Biomonitoring of $\mathrm{Hg}$ can help identify locations of greatest concern and track temporal trends of significance, especially when other environmental factors, such as climate, are rapidly changing. While effects thresholds are established for some avian invertivores and piscivores $(9,13)$ there is considerable uncertainty in concentrations of methylmercury that result in toxicity across foraging guilds and taxa. Moreover, effects thresholds are not well established for most organisms in the coastal and open oceans that support most of the world's seafood markets. In particular, tropical ecosystems with diverse fish and wildlife remain poorly characterized for patterns of methylmercury exposure and thresholds of impact, even though this biome may be most susceptible to $\mathrm{Hg}$ releases from ASGM.

\section{Next steps}

Both air and biological measurements are important for measuring and evaluating the effectiveness of the Minamata Convention (3). The Convention should be evaluated by determining key locations for comprehensive monitoring of atmospheric $\mathrm{Hg}$, and $\mathrm{Hg}$ in fish, wildlife, and humans $(14,15)$. While the ultimate goal of the Convention is to protect human health and the environment, tracking relevant changes will require a well-vetted, science-based design. Observations in the atmosphere, key terrestrial and aquatic environments, and in humans will detect progress more effectively and provide a rapid means to measure compliance.

Key needs include the following:

1) Development of a measurement infrastructure based on simple and affordable protocols that will enable traceable and comparable assessments of $\mathrm{Hg}$ and the compounds in air and deposition;

(2) Development of advanced active sensors for atmospheric mercury monitoring to facilitate the extension and management of long-term monitoring programs to support policy implementation;

3) Biological measurements conducted within a properly designed biomonitoring program within geographic areas of greatest concern for ecological and human health. 
Co-located atmospheric and biological monitoring will allow for assessment of habitats that are most sensitive to $\mathrm{Hg}$ input. Once geographic areas of concern are identified, $\mathrm{Hg}$ sources can be targeted for either more rapid phase out or implementation of $\mathrm{Hg}$ controls. Scrutiny of such areas will be important for informing policy on how to protect human and wildlife health. As humans, we have a fundamental obligation to promote actions that maintain a healthy planet with healthy ecosystems for future generations of humans and wildlife.

\section{References}

(1) Hammerschmidt, C. R. Mercury and carbon dioxide emissions: uncoupling a toxic relationship. Environ. Toxicol. Chem. 2011, 30, 2640-2646.

(2) Sunderland, E. M.; Krabbenhoft, D. P.; Moreau, J. W.; Strode, S. A.; Landing, W. M. Mercury sources, distribution, and bioavailability in the North Pacific Ocean: Insights from data and models. Global Biogeochemical Cycles 2009, 23, 2-5.

(3) UNEP. Minamata Convention on Mercury; United Nations Environment Programme: Geneva, Switzerland, 2013a; www.mercuryconventin.org.

(4) Selin, N. E. Global Biogeochemical Cycling of Mercury: A Review. Annual Review of Environment and Resources 2009, 34, 43-63.

(5) Driscoll, C. T.; Mason, R. P.; Chan, H. M.; Jacob, D. J.; Pirrone, N. Mercury as a global pollutant: sources, pathways, and effects. Environ. Sci. Technol. 2013, 47, 4967-4983.

(6) UNEP. Global Mercury Assessment 2013: Sources, Emissions, Releases and Environmental Transport; UNEP Chemicals Branch: Geneva, Switzerland, 2013b.

(7) Gustin, M. S.; Amos, H. M.; Huang, J.; Miller, M. B.; Heidecorn, K. Measuring and modeling mercury in the atmosphere: a critical review. Atmos. Chem. Phys. 2015, 15, 5697-5713.

(8) Karagas, M.; Choi, A. L.; Oken, E.; Horvat, M.; Schoeny, R.; Kamai, E.; Grandjean, P.; Korrick, S. Evidence on the human health effects of low level methylmercury exposure. Environ. Health Perspect. 2012, 120, 799-806.

(9) Scheuhammer, A. M., Basu, N.; Evers, D.C.; Heinz, G.H.; Sandheinrich, M.B.; Bank, M.S. Ecotoxicology of mercury in fish and wildlife: Recent advances. In Mercury in the Environment: Pattern and Process Bank, M., ed.; University of California Press: Berkeley, CA, 2012; pp 223-238.

(10) Lamborg, C. H.; Hammerschmidt, C. R.; Bowman, K. L.; Swarr, G. J.; Munson, K. M.; Ohnemus, D. C.; et al. A global ocean inventory of anthropogenic mercury based on water column measurements. Nature 2014, 512, 65-68.

(11) Pirrone, N.; Aas, W.; Cinnirella, S.; Ebinghaus, R.; Hedgecock, I. M.; Pacyna, J.; Sprovieri, F.; Sunderland, E. M. Toward the next generation of air quality monitoring: mercury. Atmos. Environ. 2013, 80, 599-611.

(12) Blum, J. D.; Sherman, L. S.; Johnson, M. W. Mercury Isotopes in Earth and Environmental Science. Annu. Rev. Earth Planet. Sci. 2014, 42, 249-269.

(13) Depew, D. C.; Basu, N.; Burgess, N. M.; Campbell, L. M.; Evers, D. C.; Grasman, K. A.; Scheuhammer, A. M. Derivation of screening benchmarks for dietary methylmercury exposure for the common loon (Gavia immer): rationale for use in ecological risk assessment. Environ. Toxicol. Chem. 2012, 31, 2399-2407.

(14) Evers, D. C., Keane S., Basu, N. Buck, D. Evaluating the effectiveness of the Minamata Convention on mercury: Principles and recommendations for next steps. Sci. Total Environ. Submitted.

(15) Bank, M. S.; Vignati, D. A. L.; Vigon, B. United Nations Environment Programme's global mercury partnership: science for successful implementation of the Minamata Convention. Environ. Toxicol. Chem. 2014, 33, 1199-1201. 


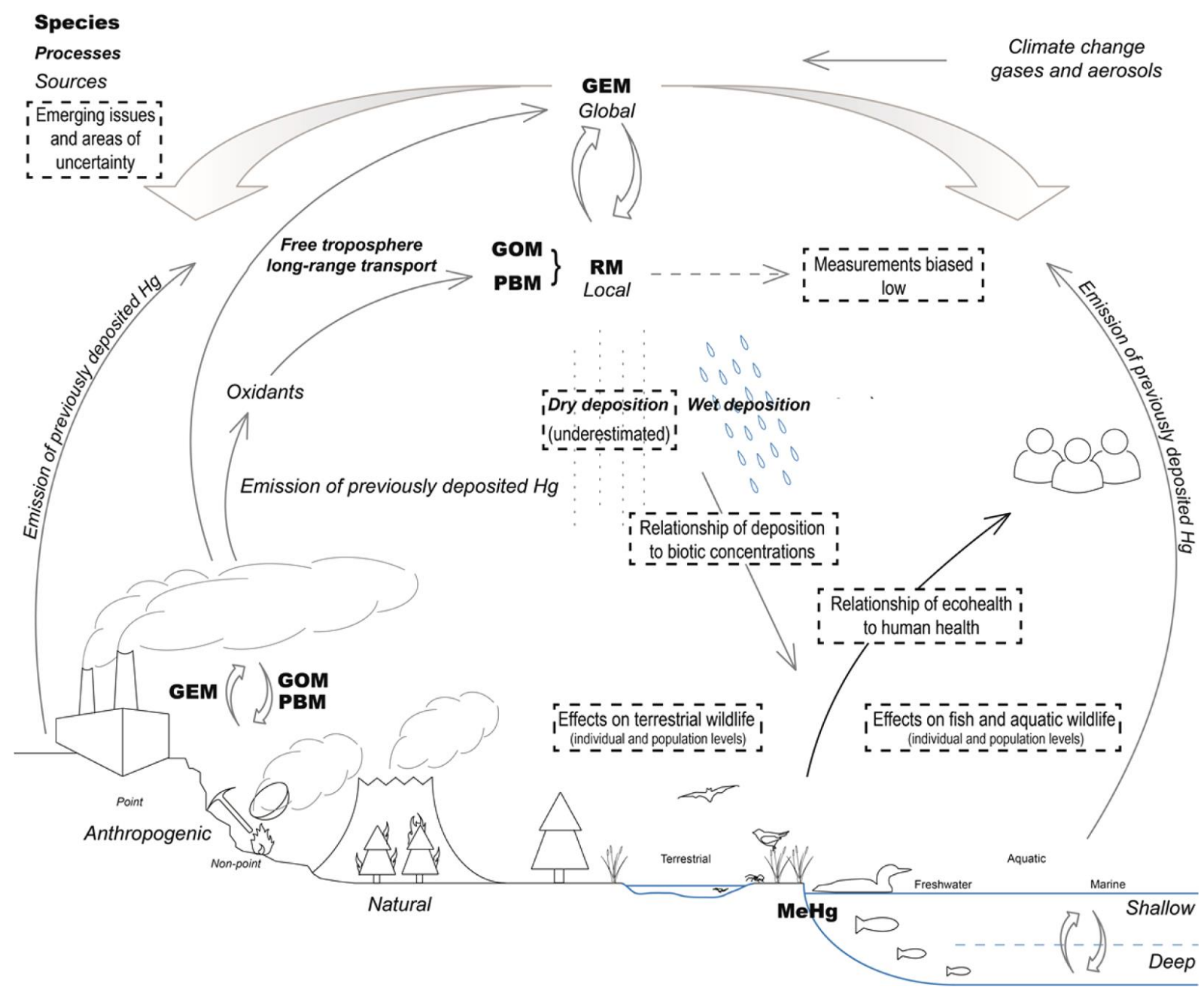

Figure 1. Simple conceptual model of the biogeochemical cycling of mercury highlighting current emerging issues and areas of uncertainty. 